\title{
Assessment of the coronary microcirculation in the cardiac catheterisation laboratory
}

\author{
Cuneyt Ada, Andy Yong \\ Department of Cardiology, Concord Repatriation General Hospital, Concord 2139, Sydney, Australia.
}

Correspondence to: Prof. Andy Yong, Department of Cardiology, Concord Repatriation General Hospital, Concord 2139, Sydney, Australia. E-mail: andy.yong@sydney.edu.au

How to cite this article: Ada C, Yong A. Assessment of the coronary microcirculation in the cardiac catheterisation laboratory. Vessel Plus 2021;5:57. https://dx.doi.org/10.20517/2574-1209.2021.51

Received: 29 Mar 2021 First Decision: 11 May 2021 Revised: 17 May 2021 Accepted: 27 May 2021 Published: 21 Dec 2021

Academic Editor: Gaetano Antonio Lanza Copy Editor: Yue-Yue Zhang Production Editor: Yue-Yue Zhang

\begin{abstract}
The coronary microcirculation is a key determinant of blood supply to the myocardium and outweighs the epicardial arteries in its abundance and distribution. Recent studies have shown the clinical benefit of assessing the microcirculation, and this practice has now been given a recommendation within the latest international guidelines and consensus statements. However, the uptake of assessing the microcirculation remains low. We continue to focus our efforts in diagnosing and managing epicardial coronary disease in the cardiac catheterisation laboratory and mostly ignore the microvasculature. This is in large part due to the lack of familiarity with available tools to perform these assessments. This review aims to summarise the various techniques available to invasively assess the coronary microcirculation in the catheterisation laboratory. The advantages, disadvantages, pitfalls and clinical implications of each method are discussed.
\end{abstract}

Keywords: Coronary microvascular disease, microvascular angina, index of microcirculatory resistance, coronary physiology

\section{INTRODUCTION}

Assessment of coronary microcirculatory function in the cardiac catheterisation laboratory is valuable for both treatment of angina ${ }^{[1]}$ and prognostication ${ }^{[2-4]}$ and has recently been incorporated into European Society of Cardiology guidelines ${ }^{[5]}$ as well as a consensus document by the European Association of Percutaneous Coronary Intervention ${ }^{[6]}$. The aim of this review is to provide a comprehensive review of the 
techniques of invasive assessment of coronary microvascular function in the cardiac catheterisation laboratory.

Indications for assessment of coronary microvascular function include, but are not limited to, ischemia and no obstructive coronary artery disease (INOCA) ${ }^{[1]}$, myocardial infarction with non-obstructive coronary $\operatorname{arteries}^{[7]}$, ST-elevation myocardial infarction (STEMI) ${ }^{[3]}$ and those with stable coronary artery disease ${ }^{[5]}$.

\section{ANATOMY, FUNCTION AND DYSFUNCTION OF THE MICROCIRCULATION}

The coronary microcirculation is broadly defined as vessels smaller than 300 microns, or more generally through pre-arterioles, arterioles, capillaries and venules ${ }^{[8]}$. In addition to serving as capacitance vessels holding $90 \%$ of the myocardial blood volume, the microcirculation is the major source of regulation of myocardial blood flow, a role which becomes vital in the presence of a stenosis where coronary autoregulation is required to maintain flow ${ }^{[9]}$. In the absence of a stenosis, the microvasculature acts in the same way to regulate flow in response to varying physiological demands such as exercise ${ }^{[10]}$.

Microvascular dysfunction is an umbrella term which encompasses multiple possible pathologies including vascular wall infiltration, extraluminal compression, sympathetic dysfunction and altered remodelling. However, the exact pathophysiological chain remains poorly understood ${ }^{[11]}$. There are now an increasing number of in vivo experimental models of coronary microvascular dysfunction which are useful in elucidating the pathophysiology of coronary microvascular dysfunction and may identify future therapeutic $\operatorname{targets}^{[12]}$.

\section{NON-INVASIVE METHODS}

Several non-invasive modalities can be used to assess the coronary microcirculation. These include positron emission tomography (PET), magnetic resonance imaging (MRI), single-photon emission computed tomography, myocardial contrast echochardiography ${ }^{[9]}$ and computed tomography $(\mathrm{CT})$ perfusion ${ }^{[13]}$. These modalities can be used to quantify myocardial blood flow both at rest and during hyperaemia using various hyperaemic agents. By then comparing resting perfusion to hyperaemic perfusion, a coronary flow reserve (CFR) can be calculated. Unlike invasive angiography, these methods are not able to directly visualise the coronary artery (except for CT) and hence cannot distinguish between causes of a low CFR including focal epicardial stenosis, diffuse epicardial stenosis and microvascular dysfunction, and this limits their capacity to reliably diagnose coronary microvascular dysfunction. As listed in Table 1, there are now a variety of invasive methods available to evaluate the coronary microcirculation that are discussed in this review.

\section{ANGIOGRAPHIC METHODS}

Coronary angiography-based techniques have historically been used to assess the status of the microvasculature with methods such as the TIMI myocardial perfusion grading system and myocardial blush grade providing indirect, qualitative measures of the state of the microvasculature. Whilst being simple, angiographic methods have poor reproducibility and accuracy ${ }^{[28]}$ and are of limited utility in the modern era with the advent of more advanced techniques as discussed below.

\section{THERMODILUTION METHODS}

\section{Index of microcirculatory resistance}

The index of microcirculatory resistance (IMR) represents the minimum achievable microvascular resistance of the circulatory bed being interrogated and hence relates directly to the amount of microvascular dysfunction present. It is measured using both pressure and thermodilution during hyperaemia and hence requires a wire which can measure both distal pressure and temperature, such as the 
Table 1. Techniques to assess for coronary microvascular dysfunction in the cardiac catheterisation laboratory

\begin{tabular}{|c|c|c|c|c|c|}
\hline Index & Ease & Method & $\begin{array}{l}\text { Normal } \\
\text { range }\end{array}$ & Advantages & Disadvantages \\
\hline $\mathbf{I M R}^{[14]}$ & +++ & Thermodilution & $<25$ & $\begin{array}{l}\text { - Specific to the microcirculation } \\
\text { - Reproducible } \\
\text { - Independent of haemodynamic } \\
\text { perturbations } \\
\text { - Predictive of subsequent death or } \\
\text { rehospitalisation in STEMI patients } \\
\text { - Predictive of subsequent MACE in } \\
\text { patients undergoing elective PCI }\end{array}$ & $\begin{array}{l}\text { - If } \mathrm{FFR}<0.45 \text {, requires wedge pressure for } \\
\text { correction }\end{array}$ \\
\hline CFR $^{[15]}$ & ++ & Thermodilution & $>2.0$ & - Predicts all-cause death & $\begin{array}{l}\text { - Cannot distinguish between macrovascular } \\
\text { and microvascular disease }\end{array}$ \\
\hline $\mathbf{R R R}^{[16]}$ & ++ & Thermodilution & $>3.5$ & $\begin{array}{l}\text { - Predicts cardiac death in a wide } \\
\text { range of patients } \\
\text { - More specific to the } \\
\text { microcirculation than CFR }\end{array}$ & - Influenced by extrinsic factors like CFR \\
\hline CFVR $^{[17]}$ & ++ & Doppler & $>2.0$ & - Predicts all-cause death & $\begin{array}{l}\text { - As with CFR, but additionally there are the } \\
\text { technical issues associated with Doppler signal } \\
\text { acquisition }\end{array}$ \\
\hline $\mathbf{h M R}^{[18,19]}$ & +++ & Doppler & $<3.0$ & $\begin{array}{l}\text { - Does not require correction } \\
\text { provided FFR is above } 0.6\end{array}$ & $\begin{array}{l}\text { - Technical issues associated with Doppler } \\
\text { signal acquisition } \\
\text { - Limited prognostic data }\end{array}$ \\
\hline $\mathbf{R}_{\text {micro }}{ }^{[20]}$ & ++ & $\begin{array}{l}\text { Continuous } \\
\text { thermodilution }\end{array}$ & $\begin{array}{l}<500 \\
\text { Woods units }\end{array}$ & $\begin{array}{l}\text { - Does not require adenosine, as the } \\
\text { saline infusion induces hyperaemia }\end{array}$ & $\begin{array}{l}\text { - Equipment not yet widely available } \\
\text { - Currently unclear how to correct for the } \\
\text { presence of a stenosis } \\
\text { - Limited prognostic data }\end{array}$ \\
\hline $\mathbf{m M R}^{[21]}$ & N/A & Doppler & Unknown & - Does not require hyperaemia & $\begin{array}{l}\text { - Requires further validation given only one } \\
\text { study available to date, published in } 2016 \\
\text { - Limited prognostic data }\end{array}$ \\
\hline IHDVPS $^{[22]}$ & + & Doppler & Not defined & $\begin{array}{l}\text { - Correlates with histological } \\
\text { microvascular abnormalities } \\
\text { - Not generally altered by most } \\
\text { haemodynamic parameters }\end{array}$ & $\begin{array}{l}\text { - Difficult to interpret in the presence of a } \\
\text { stenosis } \\
\text { - Time consuming } \\
\text { - Limited prognostic data }\end{array}$ \\
\hline $\mathbf{P}_{\mathbf{z f}}^{[23]}$ & + & Doppler & $<42 \mathrm{mmHg}$ & $\begin{array}{l}\text { - Can indicate extrinsic } \\
\text { microvascular compression in } \\
\text { STEMI }\end{array}$ & $\begin{array}{l}\text { - As with IHDVPS with the addition that data for } \\
\text { use is limited to STEMI } \\
\text { - Limited prognostic data }\end{array}$ \\
\hline $\operatorname{TFC}^{[24]}$ & ++++ & Angiography & $<21$ & - No guidewire required & $\begin{array}{l}\text { - Qualitative } \\
\text { - Limited accuracy and reproducibility }\end{array}$ \\
\hline $\mathbf{M B G}^{[25]}$ & +++ & Angiography & $2-3$ & - No guidewire required & $\begin{array}{l}\text { - Qualitative } \\
\text { - Limited accuracy and reproducibility }\end{array}$ \\
\hline IMR $_{\text {angio }}{ }^{[26]}$ & - & Angiography & As per IMR & - No guidewire required & $\begin{array}{l}\text { - Calculated on PC post-procedure } \\
\text { - Steep learning curve, difficult to perform } \\
\text { - Needs further validation } \\
\text { - Limited prognostic data }\end{array}$ \\
\hline PB-CFR $^{[27]}$ & ++ & Arterial pressure & $>2$ & $\begin{array}{l}\text { - Can be derived from pressure } \\
\text { alone }\end{array}$ & $\begin{array}{l}\text { - Poor accuracy } \\
\text { - Limited prognostic data }\end{array}$ \\
\hline
\end{tabular}

IMR: Index of microcirculatory resistance; STEMI: ST-elevation myocardial infarction; MACE: major adverse cardiovascular events; PCI: percutaneous coronary intervention; CFR: coronary flow reserve; RRR: resistive reserve ratio; CFVR: coronary flow velocity reserve; hMR: hyperaemic microvascular resistance; $R_{\text {micro: }}$ microvascular resistance (derived using continuous thermodilution); mMR: minimal microvascular resistance; IHDVPS: instantaneous hyperaemic diastolic velocity-pressure slope; Pzf: zero-flow pressure; TFC: TIMI frame count; MBG: myocardial blush grade; IMRangio: angiography-derived index of microcirculatory resistance; PB-CFR: pressure-bounded coronary flow reserve.

Pressurewire X (Abbott Vascular, Illinois, USA). The IMR is a simple and highly reproducible measure that remains stable in the presence of varying haemodynamic conditions including pacing at $110 \mathrm{bpm}$, infusion of nitroprusside and infusion of dobutaine ${ }^{[29]}$.

The normal range for IMR is $<25^{[30]}$. In stable patients, IMR has been used to identify those with microvascular angina or INOCA. These allows for targeted therapy that has been shown to improved chest pain measures and quality of life ${ }^{[1]}$ that was sustained at one year ${ }^{[31]}$. Furthermore, an abnormal IMR prior to 
elective percutaneous coronary intervention (PCI) can be used to identify those at risk of periprocedural myocardial infarction (MI) with an abnormal IMR being associated with a 23 -fold risk of periprocedural $\mathrm{MI}^{[2]}$.

In the setting of STEMI, IMR has been shown to predict outcomes and identify patients that may benefit from further intervention. Post-STEMI IMR has been shown to predict death ${ }^{[3]}$, peak creatine kinase, echocardiographic wall motion score at three months ${ }^{[4]}$, infarct size ${ }^{[32]}$, microvascular obstruction on MRI $^{[32]}$, left ventricular ejection fraction ${ }^{[33]}$ and myocardial salvage ${ }^{[33]}$. Fahrni et al. ${ }^{[34]}$ showed an elevated IMR to be associated with in increased risk of cardiac complications included but not limited to cardiac death, cardiogenic shock and pulmonary oedema.

Following primary PCI for STEMI, IMR improves appropriately in approximately two-thirds of patients; however, De Maria et al. ${ }^{[35]}$ identified one-third of patients where IMR did not improve as being either poorresponders or non-responders. These non-responders have recently been targeted as a potential population which may benefit from further therapies ${ }^{[36]}$ as an adjunct to primary PCI. Intracoronary thrombolysis has been investigated for this purpose ${ }^{[37]}$. Sezer et al ${ }^{[38]}$ administered intracoronary thrombolysis following primary PCI and showed that thrombolysis was associated with a reduction in IMR, a reduction in infarct size and preservation of left ventricular function. The RESTORE-MI trial is an ongoing randomised control study which aims to enrol patients with IMR > 32 after primary angioplasty to intracoronary tenecteplase or placebo (NCT03998319).

With an abundance of data exhibiting the value of IMR in the setting of MI and stable coronary artery disease, as well as many other clinical scenarios including a hypertrophic cardiomyopathy ${ }^{[39]}$, Takotsubo cardiomyopathy ${ }^{[40]}$ and allograft vasculopathy ${ }^{[41]}$, IMR has now been included in the European Society of Cardiology (ESC) guidelines for diagnosis of microvascular dysfunction and is recommended for patients with angina and mild or no epicardial stenosis ${ }^{[5]}$.

\section{Coronary flow reserve}

CFR is a comparison of flow at maximal hyperaemia to flow during rest. A normal CFR is above 2, meaning a doubling of flow from baseline to maximal hyperaemia ${ }^{[15]}$. CFR generally refers to thermodilution-derived CFR, whereas Doppler-derived CFR is generally referred to as coronary flow velocity reserve (CFVR). Unlike IMR, CFR is also affected by the macrocirculation as well as resting haemodynamics. Prior to the advent of fractional flow reserve (FFR), CFR was mainly used to determine severity of coronary stenoses. However, it was identified as early as 1985 that a low CFR with a normal coronary angiogram could be due to many different causes, including polycythaemia, anaemia, hypoxia and previous myocardial infarction ${ }^{[42]}$. CFR is understood to be affected by processes affecting the ability to increase flow from rest to hyperaemia. Microvascular dysfunction, or an inability of the microcirculation to vasodilate in response to hyperaemic stimuli such as adenosine, is one of these causes.

The resting component of CFR is most prone to external influence and hence is the cause of most false positive CFR results. In the presence of increased resting flow due to various haemodynamic states, the CFR may be abnormal even though the microcirculatory resistance remains low and the IMR remains normal. Hence, factors extrinsic to the coronary arteries which affect resting haemodynamics such as renal failure ${ }^{[43]}$, cirrhosis $^{[44]}$ and aortic stenosis ${ }^{[4]}$ are all causes of a low CFR. Given that CFR is non-specific, it is not surprising that, whilst CFR does predict cardiovascular death, it also predicts death from cancer and death from non-cardiovascular and non-cancer causes ${ }^{[46]}$. Furthermore, even in the setting of coronary disease, a low CFR is unable to distinguish diffuse epicardial disease from microvascular dysfunction. 


\section{Resistive reserve ratio}

The resistive reserve ratio (RRR) represents the ratio between an estimate of baseline microcirculatory resistance and hyperaemic microcirculatory resistance $[(\text { PdRest } \times \text { TmnRest }) /(\text { PdHyp } \times \text { TmnHyp })]^{[16]}$. As with CFR, this measure also compares rest to hyperaemia. However, by utilising resting Pd divided by hyperaemic Pd, it attempts to correct for disease in the epicardial vessel and is thus somewhat more specific to the microvasculature than CFR. However, because it still takes into account resting transit time (TmnRest), it is thought to be prone to extrinsic and haemodynamic factors. In a large prospective registry, comprised mostly of patients with stable coronary disease ( $90 \%)$ combined with some patients with nonculprit ACS $(\sim 10 \%)$, RRR was shown to predict all-cause death, cardiac death and death or myocardial infarction $^{[47]}$.

\section{Absolute coronary blood flow and myocardial resistance $\left(\boldsymbol{R}_{\text {micro }}\right)$}

Continuous coronary thermodilution is a novel technique to determine absolute coronary blood flow ${ }^{[48]}$ and in turn myocardial resistance $\left(\mathrm{R}_{\text {micro }}{ }^{[49]}\right.$. Using the same setup as FFR or IMR, a pressure-temperature sensing wire is placed into the distal vessel, as described in Figure 1. However, instead of utilising a hyperaemic agent such as adenosine, a specialised monorail microcatheter (Rayflow, Hexacath, Paris) is used to infuse room temperature saline at a constant rate using a dedicated infusion pump. This saline infusion induces hyperaemia, and the change in temperature caused by the saline is then detected and measured by the thermistor on the pressure wire in the distal vessel. This allows for calculation of absolute coronary blood flow, and, by dividing Pd by the flow rate, $\mathrm{R}_{\text {micro }}$ can be calculated ${ }^{[50]}$. A slower rate of saline infusion which does not lead to hyperaemia can also be used to obtain resting flow and resistance ${ }^{[51]}$ which can be used to calculate CFR and even RRR.

The main advantage of continuous thermodilution over IMR is that it is less operator dependent because saline is administered via an infusion pump rather than by $3 \mathrm{~mL}$ bolus injections in the case of IMR, CFR or RRR. Continuous thermodilution has been shown to be safe, feasible and simple to perform, even in the context of STEMI ${ }^{[49]}$. Furthermore, continuous thermodilution-derived low flow $(\mathrm{Q})$ or high $\mathrm{R}_{\text {micro }}$ has been shown to be associated with severe angina ${ }^{[52]}$. However, there are limitations associated with this method of microvascular assessment. Firstly, because of its relatively recent advent, outcome data are lacking. Secondly, there is a requirement for a specialised microcatheter. Finally, there is significant interpatient variability in $\mathrm{Q}$ and $\mathrm{R}_{\text {micro }}$ during hyperaemia owing to the difference in vascular territory supplied and hence correction for myocardial mass using computed tomography may be needed ${ }^{[53]}$ and no well-accepted normal values are available.

\section{DOPPLER BASED MEASURES}

\section{Overview}

The ComboWire XT (Philips, Hamburg, Germany) is able to measure intracoronary Doppler velocity in addition to intracoronary pressure. This allows for measurement of velocity and hence the calculation of coronary flow, without the requirement for intracoronary saline injection. While thermodilution measures flow over the whole vessel by measuring transit time from the guide to the distal wire, Doppler wires calculate vessel flow by measuring single point velocity at the level of the sensor which is usually located at the tip of the wire in the distal vessel. The average peak velocity (APV) is then taken to be equivalent to flow, assuming that the wire tip remains in the centre of the vessel and there is laminar, parabolic flow at the location of measurement.

The estimation of flow by measurement of Doppler-derived APV has technical challenges ${ }^{[30]}$. It is not known whether the presumed parabolic flow profile remains constant at different flow rates ${ }^{[54]}$. In vessels with non-significant stenoses, the hyperaemic APV was shown to be numerically more variable than resting 

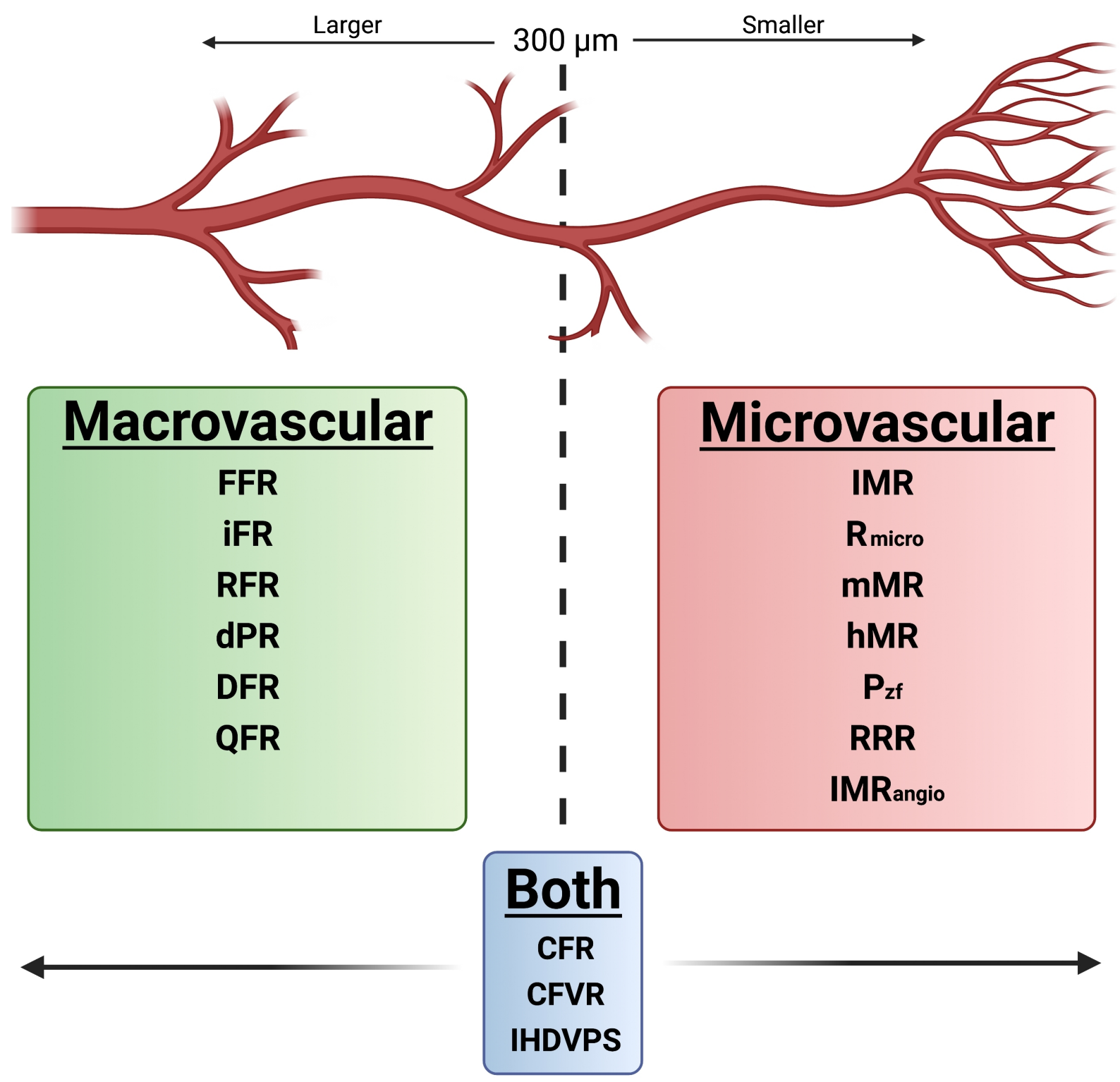

Figure 1. Coronary physiology measurements in the cardiac catheterisation laboratory. FFR: Fractional flow reserve; iFR: instantaneous wave-free ratio; RFR: resting full-cycle ratio; dPR: diastolic pressure ratio; DFR: diastolic hyperaemia-free ratio; QFR: quantitative flow ratio; IMR: index of microcirculatory resistance; $R_{\text {micro }}$ : microvascular resistance (derived by continuous thermodilution); mMR: minimal microvascular resistance; $h M R$ : hyperaemic microvascular resistance; $P_{z f}$ zero-flow pressure; RRR: resistive reserve ratio; $I M R_{\text {angio: }}$ angiography-derived index of microcirculatory resistance.

APV with a standard deviation of $13 \mathrm{~cm} / \mathrm{s} v s .5 \mathrm{~cm} / \mathrm{s}^{[5]}$. In the same patients, hyperaemic mean transit time as measured by thermodilution had a narrower range than resting mean transit time ( $0.15 \mathrm{~s} v s .0 .65 \mathrm{~s})$. The quality of Doppler data is also variable, and the same study showed $84 \%$ of thermodilution traces measurements being labelled as "good" vs. only 57\% of Doppler-derived measurements. Doppler measurements also have poor reproducibility ${ }^{[56]}$. Finally, in vessels with significant tortuosity, wire bias may lead to the tip of the wire not being in the centre of the vessel leading to an altered flow profile. Similar perturbations to flow profiles can be expected around branches and stenotic segments. When practically compared to thermodilution, Doppler is more time consuming, has a steeper learning curve and is more likely to produce inaccurate results ${ }^{[57]}$. 


\section{Hyperaemic microvascular resistance}

Hyperaemic microvascular resistance (hMR) is a Doppler-derived minimum microvascular resistance index. It is similar to IMR. However, it uses Doppler-derived velocity rather than thermodilution to calculate resistance. The steps to measure the Doppler-based hMR overlaps with IMR significantly (Figure 2, Steps 1-8), but without the additional steps of saline bolus injection (Figure 2, Steps 9-11) ${ }^{[18]}$. hMR is calculated with the formula $\mathrm{Pd} / \mathrm{APV}_{\mathrm{Hyp}}$ with no routine correction for stenosis or collateral flow performed $^{[58]}$.

While being equivalent to IMR theoretically, significant practical differences are present with at most a

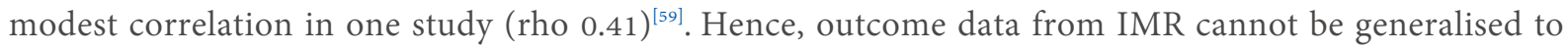
hMR. Data for hMR are somewhat limited as compared to IMR. In the post-STEMI setting, while one study showed no association with left ventricular function ${ }^{[60]}$, several studies do show prognostic significance. It has been shown that an elevated hMR predicts MRI measured microvascular injury ${ }^{[61]}$, infarct size ${ }^{[62]}$ and LV remodelling at eight months ${ }^{[63]}$, as well as a composite endpoint of death and hospitalisation for heart failure but neither of those endpoints alone ${ }^{[19]}$.

The aforementioned technical issues with Doppler measurement may be exaggerated during hyperaemia given the higher flow rates ${ }^{[54]}$, potentially causing inaccuracies, particularly in larger vessels ${ }^{[64]}$. Given the limited data and technical issues, hMR is generally reserved for research rather than clinical usage ${ }^{[57]}$.

\section{Coronary flow velocity reserve}

Coronary flow velocity reserve is the hyperaemic velocity divided by the resting velocity and is similar to CFR as measured by thermodilution. In an open-chest pig model, $\mathrm{CFR}_{\text {thermo }}$ correlated better with the directly measured CFR than CFR $_{\text {Doppler }}$ (CFVR) did. Everaars et al..$^{[55]}$ and Kern and Seto ${ }^{[65]}$ showed that $\mathrm{CFR}_{\text {Doppler }}$ was superior to $\mathrm{CFR}_{\text {thermo }}$ in terms of agreement with the current gold standard of CFR measurement, which is PET. This contradictory study has certain limitations. Firstly, a significant number of patients had a very rapid resting transit time (below $0.25 \mathrm{~s}$ ) and yet were able to an appropriate hyperaemic response with hyperaemic transit times as quick as $0.10 \mathrm{~s}$ - the combination of these two findings usually represents the wire being too close to the guide, and hence the distance is too short for accurate thermodilution. Another limitation of this study includes exclusion of $14 \%$ of Doppler traces due to poor quality, from a site recognised as having expertise in Doppler measurement ${ }^{[65]}$, a number which would likely be amplified in non-expert sites. Barbato et al. ${ }^{[6]]}$ showed that an optimal $\mathrm{CFR}_{\text {thermo }}$ could be obtained in $97 \%$ of patients, whereas an optimal CFR $_{\text {Doppler }}$ could only be obtained in $69 \%$ of patients and found a relatively good correlation between $\mathrm{CFR}_{\text {thermo }}$ and $\mathrm{CFR}_{\text {Doppler }}(r=0.79, P<0.0001)$.

Despite the abovementioned issues, CFVR, similar to CFR, has multiple studies which highlight its utility as a powerful prognostic tool. A low CFVR was found to predict revascularisation ${ }^{[6]}$, major adverse outcomes $^{[68]}$, all-cause death and cardiac mortality ${ }^{[17]}$.

\section{Minimal microvascular resistance}

Minimal microvascular resistance ( $\mathrm{mMR}$ ) is a novel index calculated by measuring the hMR in the wavefree period ${ }^{[21]}$. More specifically it is calculated during hyperaemia by multiplying the APV by Pd in the period starting $25 \%$ of the way into diastole and ending $5 \mathrm{~ms}$ before diastole. As opposed to hMR, mMR has been shown to be unaffected by obstructive stenoses. As with the corrected IMR, mMR may be used in future scenarios where microvascular resistance needs to be measured in the presence of a stenosis, but, given its relatively recent advent, further studies are required to assess its clinical utility. 
(1) Zero the guide and pressure wire pressures.

(2) Advance wire to the tip of the guiding catheter.

(3) Inject 100-200 mg of glyceryl trinitrate into coronary artery.

(4) Equalise wire pressure with aortic pressure.

(5) Advance the wire at least $6 \mathrm{~cm}$, into the distal third of the culprit vessel, and at least $3 \mathrm{~cm}$ downstream from the target lesion.

(6) Administer intracoronary glyceryl trinitrate at a dose of 100-200 micrograms.

(7) Administer intravenous infusion of adenosine $(140 \mu \mathrm{g} / \mathrm{kg} / \mathrm{min})$.

(8) Once steady state hyperaemia is achieved, record the mean aortic pressure $(\mathrm{Pa})$ and mean distal pressure $(\mathrm{Pd})$.

(9) Flush the guide catheter with room catheter saline to clear all contrast.

(10) Using a $3 \mathrm{~mL}$ Leuer-lock syringe, briskly inject a $3 \mathrm{~mL}$ bolus of room temperature saline, repeating this step 3 times and recording the average of 3 injections as the mean transit time ( $\mathrm{Tmn}_{\mathrm{hyp}}$ ).

(11) The IMR is then calculated using the formula hyperaemic $\mathrm{Pd} \times \mathrm{TmnHyp}$. If software such as Coroflow (Coroventis Research AB) is used, the corrected IMR will also automatically be calculated [calculated IMR $\left(\mathrm{IMR}_{\mathrm{calc}}\right)=$ PaxTmnHypx $\left.1.35 \times(\mathrm{Pd} / \mathrm{Pa})-0.32\right]$. The corrected IMR formula is required in the presence of significant epicardial stenosis to adjust for its physiological effects ${ }^{[7]}$

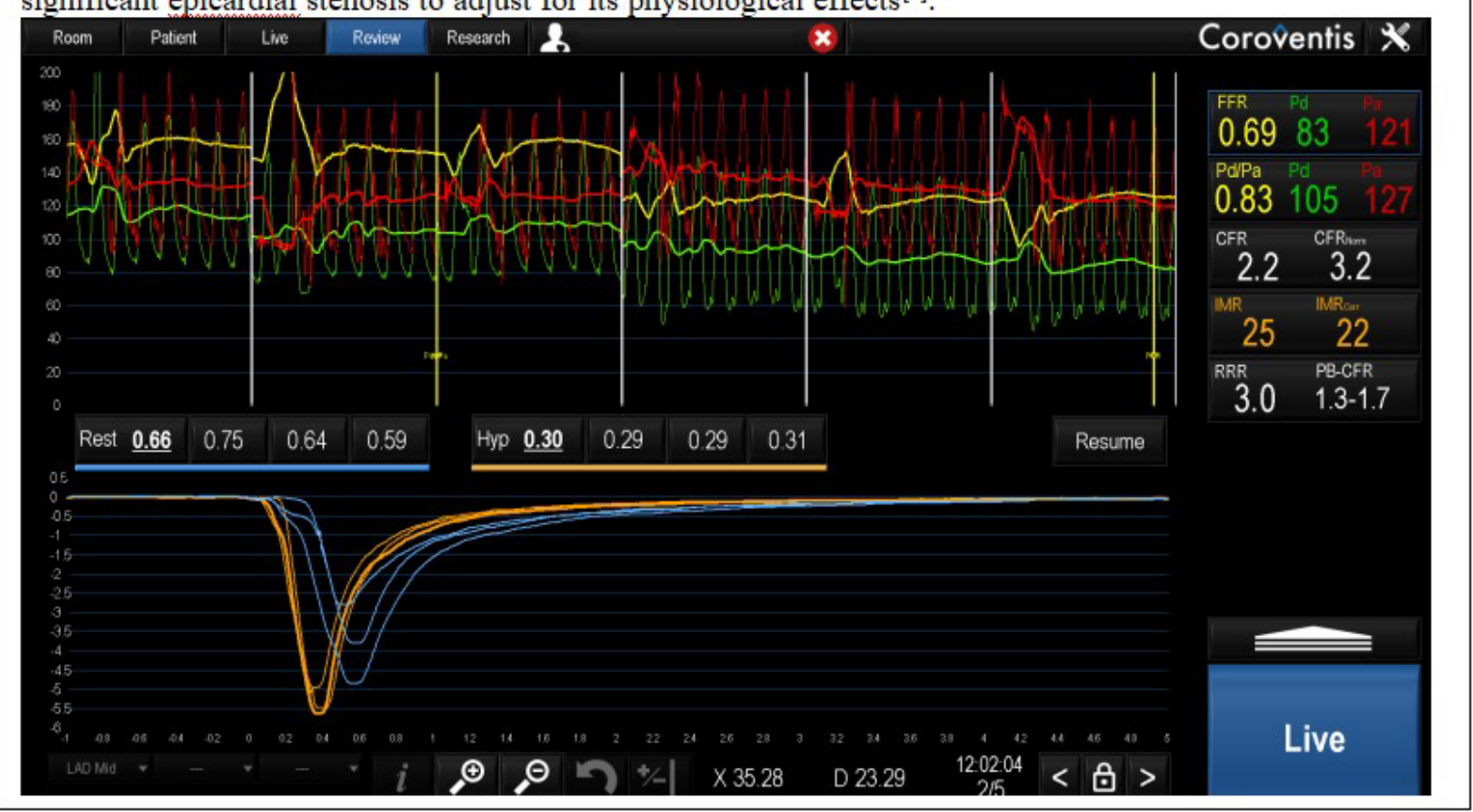

Figure 2. Measurement of IMR (and FFR). Note that Steps 1-8 are common to both FFR and IMR measurement. Steps 9-11 are additional steps required to measure IMR. IMR: Index of microcirculatory resistance; FFR: fractional flow reserve.

\section{Other Doppler derived measures: instantaneous hyperaemic diastolic velocity-pressure slope and zero-flow pressure}

The instantaneous hyperaemic diastolic velocity-pressure slope (IHDVPS) and zero-flow pressure $\left(\mathrm{P}_{\mathrm{zf}}\right)$ are both Doppler-derived measures which, similar to $\mathrm{mMR}$, are measured during hyperaemia during diastole and have to be calculated offline post hoc, as there are no commercially available systems to calculate them automatically. IHDVPS represents capacitance, which is the inverse of resistance and $\mathrm{P}_{2 \mathrm{f}}$ represents the backpressure of the coronary circulation.

Calculation of these measures requires generation of pressure-flow loops with IHDVPS being the slope of this curve in mid to late diastole and $\mathrm{P}_{\mathrm{zf}}$ being the theoretical pressure at which coronary flow would cease, and it is the pressure obtained by following the IHDVPS slope down to a velocity of $0 \mathrm{~cm} / \mathrm{s}^{[22]}$. Automation 
is possible ${ }^{[23,69]}$, but it has not become commercially available.

IHDVPS is primarily a tool for assessing stenosis severity but it has been shown to be independent of many extrinsic factors such as aortic pressure and cardiac contractility ${ }^{[70]}$. In the absence of a stenosis, while IHDVPS correlates with histological microvascular changes ${ }^{[71]}$, a normal IHDVPS still does not exclude microvascular dysfunction ${ }^{[0]}$ and its actual value in predicting microvascular dysfunction is controversial ${ }^{[22]} . \mathrm{P}_{2 \mathrm{f}}$ is sensitive to extravascular compression and has hence been shown to be of prognostic value in assessing reperfusion injury post STEMI ${ }^{[22]}$. IHDVPS and $\mathrm{P}_{z f}$ are technically challenging and timeconsuming to obtain and hence are primarily used in the research setting, even though both were conceived in the $1980 \mathrm{~s}^{[72,73]}$.

\section{PRESSURE-BOUNDED CFR}

Pressure-bounded CFR (PB-CFR) is a method which attempts to estimate CFR from the coronary pressure traces without the use of thermodilution or Doppler velocity measurement. This has been shown to have no prognostic utility in a large registry of patients with coronary artery disease ${ }^{[27]}$. In our unpublished database, we found the true thermodilution-derived CFR to fall between the PB-CFR estimated limits less than 50\% of the time. Given the aforementioned issues, PB-CFR has no clinical utility.

\section{ANGIOGRAPHY-DERIVED INDEX OF MICROCIRCULATORY RESISTANCE}

Angiography-derived index of microcirculatory resistance $\left(\mathrm{IMR}_{\text {angio }}\right)$ is a novel, wire-free method of estimating the IMR. Angiography images are acquired during hyperaemia and the hyperaemic Pa is noted. Then, off-line software QAngio ${ }^{\circ} \mathrm{XA} 3 \mathrm{D}$ (Medis, Leiden, Netherlands) is used to determine the quantitative flow reserve (QFR) as well as the "hyperaemic transit time" of the contrast by counting the number of frames taken for the contrast to travel from the guide to the distal vessel and dividing this by the number of frames per second. The hyperaemic Pa is then multiplied by the QFR to estimate the "hyperaemic Pd"[26]. IMR is then estimated using the formula $\mathrm{IMR}_{\text {angio }}=$ "hyperaemic Pd" × "hyperaemic transit time".

$\mathrm{IMR}_{\text {angio }}$ was validated in the post-STEMI setting and showed a better correlation with IMR in the infarct related artery post-primary PCI $(\rho=0.88, P<0.001)$ than in the non-infarct related artery $(\rho=0.64, P=$ 0.009). Specific outcome data for $\mathrm{IMR}_{\text {angio }}$ are not yet available. Software of this nature is very operator dependant and has a steep learning curve. Although hyperaemia is still required, $\mathrm{IMR}_{\text {angio }}$ obviates the need for a guidewire and may become more widespread in the future.

\section{CONCLUSIONS}

Microvascular assessment is a vital tool in the cardiac catheterisation laboratory, especially after its inclusion in the ESC guidelines ${ }^{[5]}$ and EAPCI consensus statement ${ }^{[6]}$. While many indices to measure microvascular status exist, only IMR, CFR and hMR have been included in these landmark documents. IMR currently appears to be the most specific and reliable. Future studies will further refine the clinical role and utility of these methods.

\section{DECLARATIONS}

\section{Acknowledgements}

Figure 1 created with BioRender.com.

\section{Authors' contributions}

Wrote and review the manuscript: Ada C, Yong A 


\section{Availability of data and materials}

Not applicable.

\section{Financial support and sponsorship}

Dr. Ada has received minor honoraria from Bayer, Boehringer-Ingelheim and Abbott Vascular. Prof. Yong has received minor honoraria and research support from Philips Healthcare and Abbott Vascular.

\section{Conflicts of interest}

Both authors declared that there are no conflicts of interest.

\section{Ethical approval and consent to participate}

Not applicable.

\section{Consent for publication}

Not applicable.

\section{Copyright}

(c) The Author(s) 2021.

\section{REFERENCES}

1. Ford TJ, Stanley B, Good R, et al. Stratified medical therapy using invasive coronary function testing in Angina: the CorMicA trial. $J$ Am Coll Cardiol 2018;72:2841-55. DOI PubMed

2. Ng MK, Yong AS, Ho M, et al. The index of microcirculatory resistance predicts myocardial infarction related to percutaneous coronary intervention. Circ Cardiovasc Interv 2012;5:515-22. DOI PubMed

3. Fearon WF, Low AF, Yong AS, et al. Prognostic value of the Index of Microcirculatory Resistance measured after primary percutaneous coronary intervention. Circulation 2013;127:2436-41. DOI PubMed PMC

4. Fearon WF, Shah M, Ng M, et al. Predictive value of the index of microcirculatory resistance in patients with ST-segment elevation myocardial infarction. J Am Coll Cardiol 2008;51:560-5. DOI PubMed

5. Knuuti J, Wijns W, Saraste A, et al. 2019 ESC Guidelines for the diagnosis and management of chronic coronary syndromes. Eur Heart J 2020;41:407-77. DOI PubMed

6. Kunadian V, Chieffo A, Camici PG, et al. An EAPCI expert consensus document on ischaemia with non-obstructive coronary arteries in collaboration with European society of cardiology working group on coronary pathophysiology \& microcirculation endorsed by coronary vasomotor disorders international study group. EuroIntervention 2021;16:1049-69. DOI PubMed

7. Pustjens TFS, Appelman Y, Damman P, et al. Guidelines for the management of myocardial infarction/injury with non-obstructive coronary arteries (MINOCA): a position paper from the Dutch ACS working group. Neth Heart J 2020;28:116-30. DOI PubMed PMC

8. Schelbert HR. Anatomy and physiology of coronary blood flow. J Nucl Cardiol 2010;17:545-54. DOI PubMed PMC

9. Feher A, Sinusas AJ. Quantitative assessment of coronary microvascular function: dynamic single-photon emission computed tomography, positron emission tomography, ultrasound, computed tomography, and magnetic resonance imaging. Circ Cardiovasc Imaging 2017;10:e006427. DOI PubMed PMC

10. Pries AR, Badimon L, Bugiardini R, et al. Coronary vascular regulation, remodelling, and collateralization: mechanisms and clinical implications on behalf of the working group on coronary pathophysiology and microcirculation. Eur Heart J 2015;36:3134-46. DOI PubMed

11. Pries AR, Reglin B. Coronary microcirculatory pathophysiology: can we afford it to remain a black box? Eur Heart J 2017;38:478-88. DOI PubMed PMC

12. Sorop O, van de Wouw J, Chandler S, et al. Experimental animal models of coronary microvascular dysfunction. Cardiovasc Res 2020;116:756-70. DOI PubMed PMC

13. Sugisawa J, Matsumoto Y, Takeuchi M, et al. Beneficial effects of exercise training on physical performance in patients with vasospastic angina. Int J Cardiol 2021;328:14-21. DOI PubMed

14. Nishi T, Murai T, Ciccarelli G, et al. Prognostic value of coronary microvascular function measured immediately after percutaneous coronary intervention in stable coronary artery disease: an international multicenter study. Circ Cardiovasc Interv 2019;12:e07889. DOI PubMed

15. Kern MJ, Lerman A, Bech JW, et al. Physiological assessment of coronary artery disease in the cardiac catheterization laboratory: a scientific statement from the American Heart Association Committee on Diagnostic and Interventional Cardiac Catheterization, Council on Clinical Cardiology. Circulation 2006;114:1321-41. DOI PubMed

16. Layland J, Carrick D, McEntegart M, et al. Vasodilatory capacity of the coronary microcirculation is preserved in selected patients with non-ST-segment-elevation myocardial infarction. Circ Cardiovasc Interv 2013;6:231-6. DOI PubMed 
17. van de Hoef TP, Bax M, Damman P, et al. Impaired coronary autoregulation is associated with long-term fatal events in patients with stable coronary artery disease. Circ Cardiovasc Interv 2013;6:329-35. DOI PubMed

18. Meuwissen M, Chamuleau SA, Siebes M, et al. Role of variability in microvascular resistance on fractional flow reserve and coronary blood flow velocity reserve in intermediate coronary lesions. Circulation 2001;103:184-7. DOI PubMed

19. de Waard GA, Fahrni G, de Wit D, et al. Hyperaemic microvascular resistance predicts clinical outcome and microvascular injury after myocardial infarction. Heart 2018;104:127-34. DOI PubMed

20. Rivero F, Gutierrez-Barrios A, Gomez-Lara J, et al. Coronary microvascular dysfunction assessed by continuous intracoronary thermodilution: a comparative study with index of microvascular resistance. Int J Cardiol 2021;333:1-7. DOI PubMed

21. de Waard GA, Nijjer SS, van Lavieren MA, et al. Invasive minimal microvascular resistance is a new index to assess microcirculatory function independent of obstructive coronary artery disease. $J$ Am Heart Assoc 2016;5:e004482. DOI PubMed PMC

22. Konijnenberg LSF, Damman P, Duncker DJ, et al. Pathophysiology and diagnosis of coronary microvascular dysfunction in STelevation myocardial infarction. Cardiovasc Res 2020;116:787-805. DOI PubMed PMC

23. Patel N, Petraco R, Dall'Armellina E, et al. Zero-flow pressure measured immediately after primary percutaneous coronary intervention for st-segment elevation myocardial infarction provides the best invasive index for predicting the extent of myocardial infarction at 6 months: an OxAMI study (Oxford Acute Myocardial Infarction). JACC Cardiovasc Interv 2015;8:1410-21. DOI PubMed

24. Gibson CM, Cannon CP, Daley WL, et al. TIMI frame count: a quantitative method of assessing coronary artery flow. Circulation 1996;93:879-88. DOI PubMed

25. 't Hof AW, Liem A, Suryapranata H, Hoorntje JC, de Boer MJ, Zijlstra F. Angiographic assessment of myocardial reperfusion in patients treated with primary angioplasty for acute myocardial infarction: myocardial blush grade. Zwolle Myocardial Infarction Study Group. Circulation 1998;97:2302-6. DOI PubMed

26. De Maria GL, Scarsini R, Shanmuganathan M, et al. Angiography-derived index of microcirculatory resistance as a novel, pressurewire-free tool to assess coronary microcirculation in ST elevation myocardial infarction. Int J Cardiovasc Imaging 2020;36:1395-406. DOI PubMed PMC

27. Ahn JM, Zimmermann FM, Johnson NP, et al. Fractional flow reserve and pressure-bounded coronary flow reserve to predict outcomes in coronary artery disease. Eur Heart J 2017;38:1980-9. DOI PubMed

28. Vicente J, Mewton N, Croisille P, et al. Comparison of the angiographic myocardial blush grade with delayed-enhanced cardiac magnetic resonance for the assessment of microvascular obstruction in acute myocardial infarctions. Catheter Cardiovasc Interv 2009;74:1000-7. DOI PubMed

29. Ng MK, Yeung AC, Fearon WF. Invasive assessment of the coronary microcirculation: superior reproducibility and less hemodynamic dependence of index of microcirculatory resistance compared with coronary flow reserve. Circulation 2006;113:2054-61. DOI PubMed

30. Fearon WF, Kobayashi Y. Invasive assessment of the coronary microvasculature: the index of microcirculatory resistance. Circ Cardiovasc Interv 2017;10:e005361. DOI PubMed

31. Ford TJ, Stanley B, Sidik N, et al. 1-year outcomes of angina management guided by invasive coronary function testing (CorMicA). JACC Cardiovasc Interv 2020;13:33-45. DOI PubMed

32. De Maria GL, Alkhalil M, Wolfrum M, et al. Index of microcirculatory resistance as a tool to characterize microvascular obstruction and to predict infarct size regression in patients with STEMI undergoing primary PCI. JACC Cardiovasc Imaging 2019;12:837-48. DOI PubMed

33. Payne AR, Berry C, Doolin O, et al. Microvascular resistance predicts myocardial salvage and infarct characteristics in ST-elevation myocardial infarction. J Am Heart Assoc 2012;1:e02246. DOI PubMed PMC

34. Fahrni G, Wolfrum M, De Maria GL, et al. Index of microcirculatory resistance at the time of primary percutaneous coronary intervention predicts early cardiac complications: insights from the OxAMI (Oxford study in acute myocardial infarction) cohort. $J \mathrm{Am}$ Heart Assoc 2017;6:e05409. DOI PubMed PMC

35. De Maria GL, Cuculi F, Patel N, et al. How does coronary stent implantation impact on the status of the microcirculation during primary percutaneous coronary intervention in patients with ST-elevation myocardial infarction? Eur Heart J 2015;36:3165-77. DOI PubMed PMC

36. De Maria GL, Alkhalil M, Borlotti A, et al. Index of microcirculatory resistance-guided therapy with pressure-controlled intermittent coronary sinus occlusion improves coronary microvascular function and reduces infarct size in patients with ST-elevation myocardial infarction: the oxford acute myocardial infarction - pressure-controlled intermittent coronary sinus occlusion study (OxAMI-PICSO study). EuroIntervention 2018;14:e352-9. DOI PubMed

37. McCartney PJ, Eteiba H, Maznyczka AM, et al. Effect of low-dose intracoronary alteplase during primary percutaneous coronary intervention on microvascular obstruction in patients with acute myocardial infarction: a randomized clinical trial. JAMA 2019;321:5668. DOI PubMed PMC

38. Sezer M, Cimen A, Aslanger E, et al. Effect of intracoronary streptokinase administered immediately after primary percutaneous coronary intervention on long-term left ventricular infarct size, volumes, and function. J Am Coll Cardiol 2009;54:1065-71. DOI PubMed

39. Gutierrez-Barrios A, Camacho-Jurado F, Diaz-Retamino E, et al. Invasive assessment of coronary microvascular dysfunction in hypertrophic cardiomyopathy: the index of microvascular resistance. Cardiovasc Revasc Med 2015;16:426-8. DOI PubMed

40. Rivero F, Cuesta J, Garcia-Guimaraes M, et al. Time-related microcirculatory dysfunction in patients with takotsubo cardiomyopathy. JAMA Cardiol 2017;2:699-700. DOI PubMed PMC 
41. Yang HM, Khush K, Luikart H, et al. Invasive assessment of coronary physiology predicts late mortality after heart transplantation. Circulation 2016;133:1945-50. DOI PubMed

42. Marcus ML, White CW. Coronary flow reserve in patients with normal coronary angiograms. J Am Coll Cardiol 1985;6:1254-6. DOI PubMed

43. Sakamoto N, Iwaya S, Owada T, et al. A reduction of coronary flow reserve is associated with chronic kidney disease and long-term cardio-cerebrovascular events in patients with non-obstructive coronary artery disease and vasospasm. Fukushima J Med Sci 2012;58:136-43. DOI PubMed

44. Yilmaz Y, Kurt R, Yonal O, et al. Coronary flow reserve is impaired in patients with nonalcoholic fatty liver disease: association with liver fibrosis. Atherosclerosis 2010;211:182-6. DOI PubMed

45. Garcia D, Camici PG, Durand LG, et al. Impairment of coronary flow reserve in aortic stenosis. J Appl Physiol (1985) 2009;106:11321. DOI PubMed

46. Gaibazzi N, Picano E, Suma S, et al. Coronary flow velocity reserve reduction is associated with cardiovascular, cancer, and noncancer, noncardiovascular mortality. J Am Soc Echocardiogr 2020;33:594-603. DOI PubMed

47. Lee SH, Lee JM, Park J, et al. Prognostic implications of resistive reserve ratio in patients with coronary artery disease. J Am Heart Assoc 2020;9:e015846. DOI PubMed PMC

48. van't Veer M, Geven MC, Rutten MC, et al. Continuous infusion thermodilution for assessment of coronary flow: theoretical background and in vitro validation. Med Eng Phys 2009;31:688-94. DOI PubMed

49. Wijnbergen I, van 't Veer M, Lammers J, Ubachs J, Pijls NH. Absolute coronary blood flow measurement and microvascular resistance in ST-elevation myocardial infarction in the acute and subacute phase. Cardiovasc Revasc Med 2016;17:81-7. DOI PubMed

50. Xaplanteris P, Fournier S, Keulards DCJ, et al. Catheter-based measurements of absolute coronary blood flow and microvascular resistance: feasibility, safety, and reproducibility in humans. Circ Cardiovasc Interv 2018;11:e006194. DOI PubMed

51. Gallinoro E, Candreva A, Colaiori I, et al. Thermodilution-derived volumetric resting coronary blood flow measurement in humans. EuroIntervention 2021. DOI PubMed

52. Konst RE, Elias-Smale SE, Pellegrini D, et al. Absolute coronary blood flow measured by continuous thermodilution in patients with ischemia and nonobstructive disease. J Am Coll Cardiol 2021;77:728-41. DOI PubMed

53. Fournier S, Keulards DCJ, van 't Veer M, et al. Normal values of thermodilution-derived absolute coronary blood flow and microvascular resistance in humans. EuroIntervention 2020. DOI PubMed

54. Fearon WF, Farouque HM, Balsam LB, et al. Comparison of coronary thermodilution and Doppler velocity for assessing coronary flow reserve. Circulation 2003;108:2198-200. DOI PubMed

55. Everaars H, de Waard GA, Driessen RS, et al. Doppler flow velocity and thermodilution to assess coronary flow reserve: a head-tohead comparison with [(15)O]H2O PET. JACC Cardiovasc Interv 2018;11:2044-54. DOI PubMed

56. Gaster AL, Korsholm L, Thayssen P, Pedersen KE, Haghfelt TH. Reproducibility of intravascular ultrasound and intracoronary Doppler measurements. Catheter Cardiovasc Interv 2001;53:449-58. DOI PubMed

57. Maznyczka AM, McCartney P, Berry C. Reference invasive tests of microvascular injury in myocardial infarction. Heart 2018;104:902. DOI PubMed PMC

58. Verhoeff BJ, van de Hoef TP, Spaan JA, Piek JJ, Siebes M. Minimal effect of collateral flow on coronary microvascular resistance in the presence of intermediate and noncritical coronary stenoses. Am J Physiol Heart Circ Physiol 2012;303:H422-8. DOI PubMed

59. Williams RP, de Waard GA, De Silva K, et al. Doppler versus thermodilution-derived coronary microvascular resistance to predict coronary microvascular dysfunction in patients with acute myocardial infarction or stable angina pectoris. Am J Cardiol 2018;121:1-8. DOI PubMed PMC

60. Hassell M, Bax M, van Lavieren MA, et al. Microvascular dysfunction following ST-elevation myocardial infarction and its recovery over time. EuroIntervention 2017;13:e578-84. DOI PubMed

61. Teunissen PF, de Waard GA, Hollander MR, et al. Doppler-derived intracoronary physiology indices predict the occurrence of microvascular injury and microvascular perfusion deficits after angiographically successful primary percutaneous coronary intervention. Circ Cardiovasc Interv 2015;8:e01786. DOI PubMed

62. Kitabata H, Imanishi T, Kubo T, et al. Coronary microvascular resistance index immediately after primary percutaneous coronary intervention as a predictor of the transmural extent of infarction in patients with ST-segment elevation anterior acute myocardial infarction. JACC Cardiovasc Imaging 2009;2:263-72. DOI PubMed

63. Kitabata H, Kubo T, Ishibashi K, et al. Prognostic value of microvascular resistance index immediately after primary percutaneous coronary intervention on left ventricular remodeling in patients with reperfused anterior acute ST-segment elevation myocardial infarction. JACC Cardiovasc Interv 2013;6:1046-54. DOI PubMed

64. Doucette JW, Corl PD, Payne HM, et al. Validation of a Doppler guide wire for intravascular measurement of coronary artery flow velocity. Circulation 1992;85:1899-911. DOI PubMed

65. Kern MJ, Seto AH. The challenges of measuring coronary flow reserve: comparisons of doppler and thermodilution to [(15)O]H2O PET perfusion. JACC Cardiovasc Interv 2018;11:2055-7. DOI PubMed

66. Barbato E, Aarnoudse W, Aengevaeren WR, et al. Validation of coronary flow reserve measurements by thermodilution in clinical practice. Eur Heart J 2004;25:219-23. DOI PubMed

67. Chamuleau SA, Tio RA, de Cock CC, et al. Prognostic value of coronary blood flow velocity and myocardial perfusion in intermediate coronary narrowings and multivessel disease. J Am Coll Cardiol 2002;39:852-8. DOI PubMed

68. Pepine CJ, Anderson RD, Sharaf BL, et al. Coronary microvascular reactivity to adenosine predicts adverse outcome in women 
evaluated for suspected ischemia results from the National Heart, Lung and Blood Institute WISE (Women's Ischemia Syndrome Evaluation) study. J Am Coll Cardiol 2010;55:2825-32. DOI PubMed PMC

69. Hoeven Nvd, Quirós A, Waard Gd, et al. TCT-523 Instantaneous Hyperemic Diastolic Velocity Pressure Slope for comprehensive physiological evaluation of epicardial and microvascular status. J Am Coll Cardiol 2016;68:B211. DOI

70. Ganz P, Hsue PY. Assessment of structural disease in the coronary microvasculature. Circulation 2009;120:1555-7. DOI PubMed

71. Escaned J, Flores A, Garcia-Pavia P, et al. Assessment of microcirculatory remodeling with intracoronary flow velocity and pressure measurements: validation with endomyocardial sampling in cardiac allografts. Circulation 2009;120:1561-8. DOI PubMed

72. Feigl EO. Coronary physiology. Physiol Rev 1983;63:1-205. DOI PubMed

73. Mancini GB, McGillem MJ, DeBoe SF, Gallagher KP. The diastolic hyperemic flow versus pressure relation. a new index of coronary stenosis severity and flow reserve. Circulation 1989;80:941-50. DOI PubMed

74. Yong AS, Layland J, Fearon WF, et al. Calculation of the index of microcirculatory resistance without coronary wedge pressure measurement in the presence of epicardial stenosis. JACC Cardiovasc Interv 2013;6:53-8. DOI PubMed 